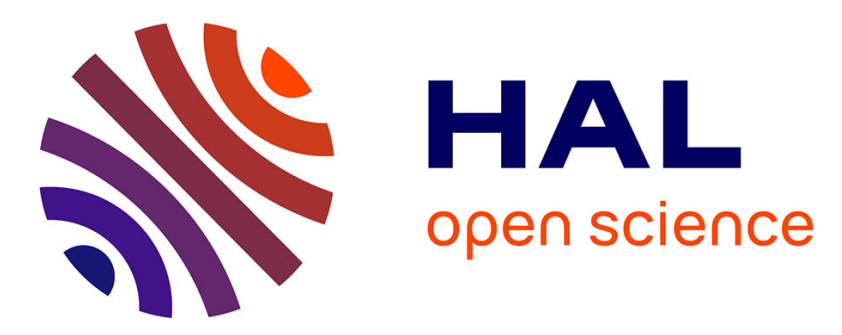

\title{
On the Effectiveness of Single and Multiple Base Station Sleep Modes in Cellular Networks
}

Marco Ajmone Marsan, Luca Chiaraviglio, Delia Ciullo, Michela Meo

\section{To cite this version:}

Marco Ajmone Marsan, Luca Chiaraviglio, Delia Ciullo, Michela Meo. On the Effectiveness of Single and Multiple Base Station Sleep Modes in Cellular Networks. [Research Report] RR-8186, INRIA. 2012. hal-00759399

\author{
HAL Id: hal-00759399 \\ https://hal.inria.fr/hal-00759399
}

Submitted on 17 Dec 2012

HAL is a multi-disciplinary open access archive for the deposit and dissemination of scientific research documents, whether they are published or not. The documents may come from teaching and research institutions in France or abroad, or from public or private research centers.
L'archive ouverte pluridisciplinaire HAL, est destinée au dépôt et à la diffusion de documents scientifiques de niveau recherche, publiés ou non, émanant des établissements d'enseignement et de recherche français ou étrangers, des laboratoires publics ou privés. 
On the Effectiveness of Single and Multiple Base Station Sleep Modes in Cellular Networks

Marco Ajmone Marsan, Luca Chiaraviglio, Delia Ciullo, Michela Meo

RESEARCH 



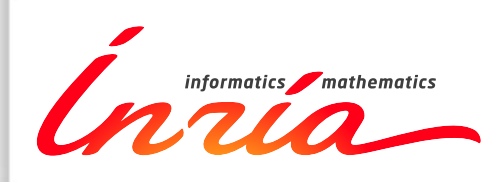

\title{
On the Effectiveness of Single and Multiple Base Station Sleep Modes in Cellular Networks
}

\author{
Marco Ajmone Marsan*, Luca Chiaraviglio ${ }^{\dagger}$, Delia Ciullo ${ }^{\ddagger}$, \\ Michela Meo $\S$
}

Project-Teams Maestro

Research Report n 8186 - December 2012 - 24 pages

Some of the results in this paper have been presented in [1] and [2].

* Politecnico di Torino, Italy, Imdea Networks, Spain, ajmone@polito.it

$\dagger$ Inria Sophia Antipolis, France, luca.chiaraviglio@inria.fr

¥ Inria Sophia Antipolis, France, delia.ciullo@inria.fr

$\S$ Politecnico di Torino, Italy, michela.meo@polito.it

\section{RESEARCH CENTRE}

SOPHIA ANTIPOLIS - MÉDITERRANÉE

2004 route des Lucioles - BP 93

06902 Sophia Antipolis Cedex 


\begin{abstract}
In this paper we study base station sleep modes that, by reducing power consumption in periods of low traffic, improve the energy efficiency of cellular access networks. We assume that when some base stations enter sleep mode, radio coverage and service provisioning are provided by the base stations that remain active, so as to guarantee that service is available over the whole area at all times. This may be an optimistic assumption in the case of the sparse base station layouts typical of rural areas, but is, on the contrary, a realistic hypothesis for the dense layouts of urban areas, which consume most of the network energy.

We consider the possibility of either just one sleep mode scheme per day (bringing the network from a high-power, fully-operational configuration, to a low-power reduced configuration), or several sleep mode schemes per day, with progressively fewer active base stations. For both contexts, we develop a simple analytical framework to identify optimal base station sleep times as a function of the daily traffic pattern.

We start by considering homogeneous networks, in which all cells carry the same amount of traffic and cover areas of equal size. Considering both synthetic traffic patterns and real traffic traces, collected from cells of an operational network, we show that the energy saving achieved with base station sleep modes can be quite significant, the actual value strongly depending on the traffic pattern. Our results also show that most of the energy saving is already achieved with one sleep mode scheme per day. Some additional saving can be achieved with multiple sleep mode schemes, at the price of a significant increase in complexity.

We then consider heterogeneous networks in which cells with different coverage areas and different amounts of traffic coexist. In particular, we focus on the common case in which some micro-cells provide additional capacity in a region covered by an umbrella macro-cell, and we prove that the optimal scheduling of micro-cell sleep times is in increasing order of load, from the least loaded to the most loaded. This provides a valuable guideline for the scheduling of sleep modes (i.e., of low-power configurations) in complex heterogeneous networks.
\end{abstract}

Key-words: Energy-efficiency, Cellular networks, QoS and sleep modes 


\section{L'efficacité des modes de sommeil uniques et multiples pour les stations de base dans les réseaux cellulaires}

Résumé : Dans ce rapport, nous étudions les modes de mise en veille des stations de base. En réduisant la puissance en période de trafic faible, l'efficacité énergétique des réseaux d'accès cellulaires se trouve améliorée. Nous supposons que le service est toujours disponible sur tout le réseau. Ainsi, lorsque certaines stations de base sont mises en veille, les stations de base restant actives assurent la couverture radio et la fourniture de services. Cette hypothèse peut sembler optimiste là où les stations de base sont éparses (cas typique des zones rurales) mais elle est réaliste dans les zones urbaines, qui correspondent au pic de la consommation énergétique du réseau. Deux scénarios de mise en veille sont considérés : dans le premier, la mise en veille est effectuée une seule fois par jour sur tout le réseau, celui-ci passe alors d'une configuration entièrement fonctionnelle à une configuration réduite; dans le deuxième scénario, le nombre des stations de base actives est progressivement réduit au cours de la journée. Pour chaque scénario, nous développons une analyse simple pour identifier les durées optimales de mise en veille selon le trafic journalier. Dans un premier temps, nous considérons le cas homogène dans lequel toutes les cellules transportent la même quantité de trafic et ont des zones de couvertures identiques. Nous montrons sur des traces de trafic d'abord synthétiques ensuite réelles (fournies par un opérateur) que l'économie d'énergie réalisée avec la mise en veille des stations de base peut être très importante, sa valeur dépendant fortement de la nature du trafic. Nos résultats montrent également que l'économie d'énergie réalisée est obtenue majoritairement avec une seule mise en veille journalière dans le réseau. La réduction progressive du nombre de stations actives apporte certes un surplus d'économie d'énergie, mais au prix d'une augmentation significative de la complexité. Dans un second temps, nous considérons le cas hétérogène dans lequel des cellules de zones de couverture différentes et de trafic différent coexistent. Nous nous concentrons en particulier sur le cas courant dans lequel certaines micro-cellules fournissent une capacité supplémentaire dans une région couverte par une macro-cellule et prouvons que l'ordonnancement optimal des mises en veille des micro-cellules est selon l'ordre croissant de la charge. Ceci fournit une indication importante pour la planification des mises en veille dans les réseaux hétérogènes complexes.

Mots-clés : Efficacité énergétique, réseaux cellulaires, QoS et modes de sommeil 


\section{Introduction}

Eskimos are said to use many words for snow, because snow pervades their environment. On the contrary, in the early days of networking, the term power was used to identify the ratio of throughput over delay [3,4], because energy issues did not belong in the networking landscape. Then, cellular networks and battery-operated terminals (most notably mobile phones) came along, and power control (now real power, measured in $\mathrm{J} / \mathrm{s}$ ) became an issue, in order to extend both the distance from the base station at which a terminal could be used, and the battery charge duration (in the early '90s, heavy users carried a spare charged battery in their pocket, to avoid being cut off around noon). Next, sensor networks brought with them the question of power minimization to increase the network lifetime. Still, before the turn of the century, power consumption was not an element of the wired network design space. The first paper that addressed energy issues in fixed networks was [5], where Gupta and Singh investigated the energy consumption of Internet devices, and discussed the impact of sleep modes on network protocols. Since then, the interest in energy-efficient networking has been steadily rising, and the energy issue is now addressed in many conferences and research projects, among which we wish to mention TREND (Towards Real Energy-efficient Network Design) [6], the Network of Excellence funded by the European Commission within its 7th Framework Programme, which supported the work reported in this paper.

The directions that are presently pursued to achieve energy efficiency in networking can be grouped in two classes: 1) development of new technologies that reduce energy consumption, and 2) identification of approaches that make the network energy consumption proportional to traffic. The rationale for the second direction derives from the observation that today network equipment exhibits power consumption which is practically independent of load. For example, a base station of a cellular network consumes at zero load about $60-80 \%$ of the energy consumption at full load [7].

Approaches that aim at improving the proportionality between the network energy consumption and the network load can be further divided in 2 sub-classes: $2 \mathrm{a}$ ) development of equipment exhibiting better proportionality of energy consumption to load, and $2 \mathrm{~b}$ ) identification of algorithms that allow the reduction of the functionality of network equipment in periods of low traffic, so as to decrease energy consumption in such periods. The algorithms that received most attention in class $2 \mathrm{~b}$ are often called speed scaling, and sleep modes. By speed scaling we normally mean that the equipment can operate at different clock rates, with lower rates corresponding to lower power (and lower performance). By sleep modes we mean that in periods of low traffic the network operates with a subset of its equipment, the rest being switched off to save energy.

In the case of cellular networks, the critical equipment for power consumption is the base station (BS), whose typical consumption ranges between $0.5 \mathrm{~kW}$ and $2 \mathrm{~kW}$ [8, 9], including power amplifiers, digital signal processors, feeders, and cooling system. Moreover, according to [10], all together, the BSs make up for about $80 \%$ of the total energy consumption of the cellular network.

In this paper we consider sleep modes for BSs in cellular networks, with reference to $3 \mathrm{G}$ technology, and we investigate the benefits that can be achieved by putting to sleep, i.e., bringing to a low-power-idle (LPI) state, a BS during periods of low traffic. This means that, in the future, the cellular access network planning should allow the selection of different operational layers corresponding to network configurations that specify the set of active BSs to serve different levels of traffic. These configurations can be activated according to predefined schedules, that are derived based on a combination of traffic forecasts and logs of traffic measurements. We compute the maximum amount of energy that can be saved with this approach, and we study the impact of the number of configurations, considering different types of network topologies with idealized 
cell structures, as well as a real BS layout and a very realistic coverage map.

We assume that when some BSs are in sleep mode, radio coverage and service provisioning are taken care of by the base stations that remain active, so as to guarantee that service is available over the whole area at all times. This may be an optimistic assumption in the case of sparse base station layouts in rural areas (where network planning usually aims at coverage using large cells), but is on the contrary a realistic hypothesis for the dense layouts of urban areas (where network planning normally aims at capacity, with very redundant coverage, based on few large and many small cells), which consume most of the network energy. When some BSs enter the LPI state, the base stations that remain active may need to increase their transmission power, so as to cover also the area that was covered by the sleeping BSs. However, in our previous study [18] we showed that this increment is usually negligible.

The main contributions of this paper are the following. We develop an analytical framework to identify the optimal scheduling of low-power network configurations (including how many BSs should be put into sleep mode and when) as a function of the daily traffic pattern, in the cases in which either just one low-power configuration per day is possible (bringing the network from a high-power, fully-operational configuration, to a low-power reduced-capacity configuration), or several low-power configurations per day are permitted (progressively reducing the number of active base stations, the network capacity, and the network power). We then compute the achievable energy savings in several cases: i) assuming that any fraction of base stations can be put to sleep, ii) accounting for the constraints resulting from typical regular base station layouts, and iii) considering the case of a realistic network deployment. Moreover, we consider heterogeneous networks in which coverage is obtained by the superposition of macro-cells, that act as umbrella cells, and micro-cells, that provide additional capacity in specific areas. We prove that the optimal scheduling according to which micro-cells should be put to sleep is in order of increasing load, and that large saving can be achieved in this case as well.

The rest of the paper is organized as follows. Section 2 reviews the related literature. Optimal energy savings schemes for homogeneous networks are presented in Section 3. Savings on regular configurations are computed in Section 3.5. Section 4 details the analysis of heterogeneous networks, and provides a case study of a real network. Finally, Section 5 concludes the paper.

\section{Related Work}

The fact that BSs are the most energy-greedy components of cellular networks, and are often under-utilized, was realized only few years ago [10,11, 12, 13]. Since then, several approaches have been pursued to reduce the carbon footprint of BSs, ranging from the use of renewable energy sources [14], to the improvement of hardware components [15], to cell zooming techniques [16], to the adoption of sleep modes. As regards sleep modes, starting from our early works $[17,1,18]$, it has been shown that sleep modes adoption for BSs is an efficient solution that allows a significant amount of energy to be saved during low traffic periods. Later, also the authors of [19] showed, using real data traces, that promising potential savings are achievable by turning off BSs during low traffic periods. Recently, in [20] the authors have investigated energy savings in dynamic BS operation and the related problem of user association, showing that their algorithms can significantly reduce the energy consumption. A distributed solution to switch off underutilized BSs when traffic is low, and switch them on when the traffic is high, was proposed in [21]; large savings, that depend on temporal-spatial traffic dynamics, are shown to be possible.

Besides BSs switch-off, sleep modes can be enabled also considering different options, ranging from the reduction of the number of active transmitters [22], to the switch-off of a whole network, when coverage is provided by other technologies of the same operator, or when several operators 


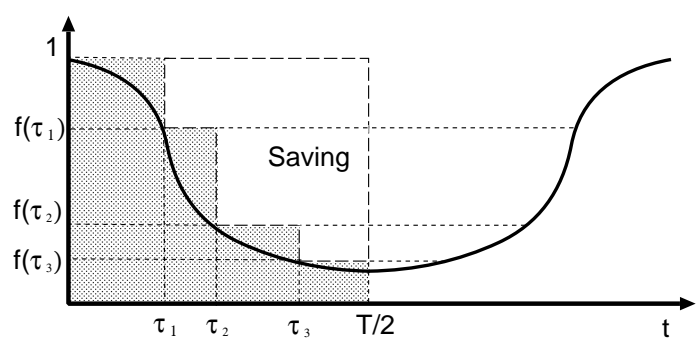

Figure 1: Example of multiple sleep schemes with $N=3$.

offer coverage in the same service area [23], by allowing customers to roam from the network that switches off to one that remains on.

Differently from most previous works, but expanding our analysis in [1] and [2], here we analytically characterize the maximum energy savings that can be achieved in regular networks, under a given traffic profile. In particular, we analytically show that the optimal trade-off between energy savings and complexity in network management is obtained when only few lowpower configurations per day are allowed, and BSs are put to sleep according to increasing load. These results are also corroborated by a case-study analysis.

The extensions that we provide with respect to [1] and [2] are mainly the following: i) we consider a more realistic energy consumption model, ii) we consider the case of multiple, progressive low-power configurations per day, proving that small numbers of configurations are sufficient to achieve most of the possible energy savings; iii) we prove that the optimal sleep order consists in putting BSs to sleep in increasing order of load; iv) we consider different cell types (business and residential); v) we obtain analytical results from a more detailed synthetic traffic pattern, and vi) we consider as a case study the heterogeneous BS layout in a square of 800 by $800 \mathrm{~m}$ in downtown Munich, with real traffic profiles, resulting from measurements in an operational network.

\section{Optimal Sleep Modes in Homogeneous Networks}

In this section we propose a simple analytical framework to compute the maximum energy saving that can be achieved by properly scheduling multiple low-power network configurations in homogeneous networks. We first consider an idealized synthetic traffic profile, that we call two-step traffic pattern, for which we easily obtain analytical results. Then, we present results obtained with some measured traffic patterns collected from a cellular network in operation.

\subsection{The network and traffic model}

Let $f(t)$ be the daily traffic pattern in a cell, i.e., the traffic intensity as a function of time $t$, with $t \in[0, T], T=24 \mathrm{~h}$, and $t=0$ at the peak hour; $f(t)$ is normalized to the peak hour traffic, so that $f(0)=1$. As an example, in Fig. 1 we report a typical daily traffic pattern that, for simplicity, is symmetric around $T / 2$. We assume that $f(t)$ is a continuous and differentiable function of $t$.

The cellular access network is dimensioned so that at peak traffic a given QoS constraint is met. Clearly, if the QoS constraint is met under peak traffic $f(0)$, it is also met for lower values of traffic intensity, and thus during the whole day. For analytical tractability, we assume that in the considered area all cells have identical traffic patterns; thus, we say that the network is 
homogeneous. We recognize that BSs deployed in real networks can be subjected to different traffic patterns, and we will consider traffic heterogeneity in Section 4.

Consider an area with $M$ homogeneous cells and consider a low-power network configuration $\Phi$ such that, during periods of low traffic, a fraction $x<1$ of the cells, i.e., $x M$ cells, are active, while the remaining fraction, $1-x$, of the cells (actually, of the respective BSs) are in LPI (or sleep) mode. When the low-power configuration $\Phi$ is applied, the $x M$ active BSs have to sustain, in addition to their own traffic, the traffic that in normal conditions is taken care of by the $(1-x) M$ sleeping BSs; thus, their traffic becomes:

$$
f^{(\Phi)}(t)=f(t)+\frac{(1-x) M}{x M} f(t)=\frac{1}{x} f(t)
$$

i.e., an active cell receives $1 / x$ times its own traffic ${ }^{1}$. Thus, to always satisfy the QoS constraint, $\Phi$ can be applied whenever the traffic $f(t)$ is so low that $f^{(\Phi)}(t)$ is still below 1 , that is the peak hour traffic; this is what we call the load constraint,

$$
f^{(\Phi)}(t)=\frac{1}{x} f(t)<1
$$

Starting from the peak hour, with decreasing $f(t)$, the earliest time instant $\tau$ in which $\Phi$ can be applied is defined by,

$$
f^{(\Phi)}(\tau)=1
$$

so that,

$$
\tau=f^{-1}(x)
$$

By assuming that the low-power configuration $\Phi$ is applied as soon as the traffic profile permits, the scheme $\Phi$ is fully specified by the value of $\tau$. Considering, for simplicity, a daily traffic pattern that is symmetric around $T / 2$, i.e., such that $f(\tau)=f(T-\tau)$ with $\tau \in[0, T / 2]$, and assuming that $f(t)$ is monotonically decreasing in $[0, T / 2]$, the period in which $\Phi$ can be applied starts in $\tau$ and lasts for the whole time in which the traffic intensity is below $f(\tau)=x$, i.e., for a period of duration $T-2 \tau$.

\subsection{The energy consumption model}

Coherently with the assumption of a homogeneous network, we assume that in the considered area all BSs have identical power consumption. Actually, BSs deployed in real networks may consume a different amount of power (e.g., due to different technology); however, the assumption that all the BSs consume the same amount of power is reasonable, at least in some portions of dense urban areas.

For each BS, we assume that the power consumption equals $W_{L P I}$ in the LPI state, i.e., when the BS is in sleep mode. Instead, when the BS carries a traffic $f(t)$, its power consumption can be expressed as

$$
P(t)=W_{L P I}+W_{0}+W_{T} f(t)
$$

where $W_{0}$ is the power necessary for an active BS carrying zero traffic, in addition to $W_{L P I}$, and $W_{T}$ is the power necessary for the BS to handle one unit of traffic. Note that, in our computations, we will consider the normalized values of the three power components, such that the sum is equal to one when the traffic is maximum (i.e., equal to one).

\footnotetext{
${ }^{1}$ Note that (1) holds for the case of just one low-power network configuration, $\Phi$, in an area where $M$ cells are deployed. We discuss the case of several low-power configurations next.
} 
Obviously, the values of $W_{L P I}, W_{0}$, and $W_{T}$ depend on the BS technology and model, but normally the $W_{0}$ component dominates (see for example [9]). Typically, the higher is the power consumption in the LPI state, the shorter is the BS activation time. Therefore, the values of $W_{L P I}$ depend on the policy that an operator may want to adopt, based on activation and deactivation times of BSs. In our computations, we will use low values of $W_{L P I}$, since we assume the BSs are put in LPI state only a few times per day. This implies that activation/deactivation times, even if long in absolute terms (e.g., tens of seconds or even few minutes), can be considered negligible with respect to long sleep time intervals.

The energy consumed in a day by a BS in a cellular network in which all BSs remain always on is

$$
\begin{aligned}
E_{A L L O N} & =\int_{0}^{T}\left(W_{L P I}+W_{0}+W_{T} f(t)\right) d t \\
& =T\left(W_{L P I}+W_{0}\right)+W_{T} \int_{0}^{T} f(t) d t
\end{aligned}
$$

Consider now a network in which the low-power configuration $\Phi$ is applied at time $\tau$. In this case, the BSs have different daily consumption, depending on whether they are always on or they enter sleep mode when traffic is low. The energy consumed in a day by a BS which is put to sleep according to configuration $\Phi$ is equal to

$$
\begin{aligned}
E_{S L E E P} & =2 \int_{0}^{\tau}\left(W_{L P I}+W_{0}+W_{T} f(t)\right) d t \\
& +2(T / 2-\tau) W_{L P I} \\
& =T W_{L P I}+2 \tau W_{0}+2 W_{T} \int_{0}^{\tau} f(t) d t
\end{aligned}
$$

because from 0 to $\tau$ and from $T-\tau$ to $T$ the BS is on, while for the rest of the day the BS is in the LPI state. The energy consumed in a day by a BS which remains on while other cells are put to sleep according to configuration $\Phi$ is equal to

$$
\begin{aligned}
E_{O N} & =2 \int_{0}^{\tau}\left(W_{L P I}+W_{0}+W_{T} f(t)\right) d t \\
& +2 \int_{\tau}^{T / 2}\left(W_{L P I}+W_{0}+W_{T} \frac{1}{x} f(t)\right) d t \\
& =T\left(W_{L P I}+W_{0}\right)+2 W_{T} \int_{0}^{\tau} f(t) d t \\
& +2 W_{T} \frac{1}{x} \int_{\tau}^{T / 2} f(t) d t
\end{aligned}
$$

because from 0 to $\tau$ and from $T-\tau$ to $T$ the BS carries only its traffic share, while for the rest of the day the BS carries also a portion of the traffic of the BSs in the LPI state.

Considering that a fraction $1-x$ of the BSs is put to sleep according to configuration $\Phi$, while the remaining fraction $x$ remains on, the average energy consumption of a BS is

$$
\begin{aligned}
E_{\Phi} & =(1-x) E_{S L E E P}+x E_{O N} \\
& =T W_{L P I}+[2(1-x) \tau+T x] W_{0} \\
& +2 W_{T} \int_{0}^{\tau} f(t) d t+2 x W_{T} \frac{1}{x} \int_{\tau}^{T / 2} f(t) d t \\
& =T W_{L P I}+T W_{0}-(1-x)[T-2 \tau] W_{0} \\
& +W_{T} \int_{0}^{T} f(t) d t
\end{aligned}
$$

Thus, the energy saved by using configuration $\Phi$ with respect to the always-on case is:

$$
S=E_{A L L O N}-E_{\Phi}=(1-x)[T-2 \tau] W_{0}
$$

which corresponds to saving the power $W_{0}$ for the fraction of cells in LPI state, and for the period in which the low-power configuration $\Phi$ is used. The fact that no traffic is lost is reflected in the independence of $S$ from $W_{T}$. In the numerical results that we will report in what follows we will often use the percentage saving obtained by dividing $S$ by $E_{A L L O N}$. 
Let us now focus on the case of multiple low-power configurations in which $N$ low-power network configurations are allowed per day, each configuration being denoted by $\Phi_{i}$ with $i=$ $1, \ldots, N$. In particular, given a decreasing traffic profile $f(t)$, symmetric around $T / 2$, we assume that the configurations $\Phi_{i}$ are ordered in such a way that the fraction of BSs in sleep mode increases with $i$. In other words, we assume to put to sleep a fraction $\left(1-x_{1}\right)$ of BSs at a certain time instant $\tau_{1}$, a fraction $\left(1-x_{i}\right)$ at $\tau_{i}, \ldots$, and $\left(1-x_{N}\right)$ at $\tau_{N}$, with $x_{1}>\cdots>x_{i}>\cdots>x_{N}$. Let the $N$-dimensional vector $\bar{\tau}$ collect the switching instants $\tau_{i}$, i.e., $\bar{\tau}=\left[\tau_{1}, \tau_{2}, \cdots, \tau_{N}\right]$. Extending (10), the energy saving with respect to the always-on case is,

$$
S_{N}(\bar{\tau})=2 W_{0} \sum_{i=1}^{N}\left(\tau_{i+1}-\tau_{i}\right)\left(1-f\left(\tau_{i}\right)\right)
$$

with $\tau_{N+1}=T / 2$. Indeed, with reference to Fig. 1 for the case $N=3$, the saving is given by the white area made of three rectangles and, for example, from $\tau_{1}$ to $\tau_{2}$ the saving is given by $1-f\left(\tau_{1}\right)\left(\tau_{2}-\tau_{1}\right)$, from $\tau_{2}$ to $\tau_{3}$ the saving is given by $1-f\left(\tau_{2}\right)\left(\tau_{3}-\tau_{2}\right)$, and so on.

The saving can be maximized (and the consumption minimized) by choosing the configurations $\Phi_{i}$ so as to maximize $S_{N}(\bar{\tau})$. Assuming that the function $S_{N}(\bar{\tau})$ is piecewise differentiable and convex (these conditions are satisfied by construction given the conditions we imposed on $f(\tau)$ ), the optimal choice of the schemes, i.e., the optimal $\bar{\tau}$, namely $\bar{\tau}^{*}$, is such that $\partial S_{N}(\bar{\tau}) / \partial \tau_{i}=0$, for $i=1, \cdots, N$. The optimal scheme is given by the solution of the following system of equations,

$$
-f^{\prime}\left(\tau_{i}\right)\left(\tau_{i+1}-\tau_{i}\right)+f\left(\tau_{i}\right)-f\left(\tau_{i-1}\right)=0,
$$

with $i=1, \ldots, N$, and $f^{\prime}(t)$ is the derivative of $f(t)$ with respect to time $t$, and $\tau_{0}=0$ (so that $f\left(\tau_{0}\right)=1$ ) and $\tau_{N+1}=T / 2$. Notice that there may exist different schemes corresponding to the same consumption, and there may exist different solutions of (12) that are local maxima of (11); among these values, one of those leading to $S\left(\bar{\tau}^{*}\right)$ can be selected as the optimum. For example, in Fig. 2, two (single) low traffic configurations corresponding to time instants $\tau_{1}$ and $\tau_{2}$ lead to the same energy saving.

The corresponding maximum energy saving is denoted by $S_{N}$ and it represents the best that can be done under traffic $f(t)$ by allowing the network to move across $N$ different low-power configurations.

An upper bound to the achievable network saving can be obtained by considering that the fraction of BSs that is in sleep mode increases in a continuous way, through infinitesimal increments. In other terms, the upper bound of the saving, namely $S^{U}$, can be computed as the complement of the integral of $f(t)$,

$$
S^{U}=2 W_{0} \frac{2}{T} \int_{0}^{T / 2}(1-f(\tau)) d \tau
$$

In the case of a non-symmetric traffic pattern $f(t)$, it can be easily shown that the optimum scheme can be derived in a similar way, by solving the derivative of the saving $S_{N}(\bar{\tau})$ that corresponds to the asymmetric profile.

\subsection{A synthetic traffic pattern}

To start analyzing the effect of the number of network configurations used in a day, we consider a synthetic traffic pattern, that, while being very simple, allows us to tune the traffic shape by acting on a single scalar parameter. We consider the family of two-step traffic profiles plotted in 


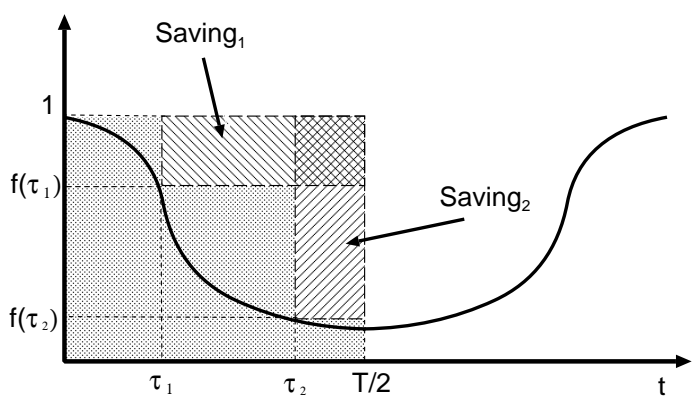

Figure 2: Two schemes achieving the same energy saving.

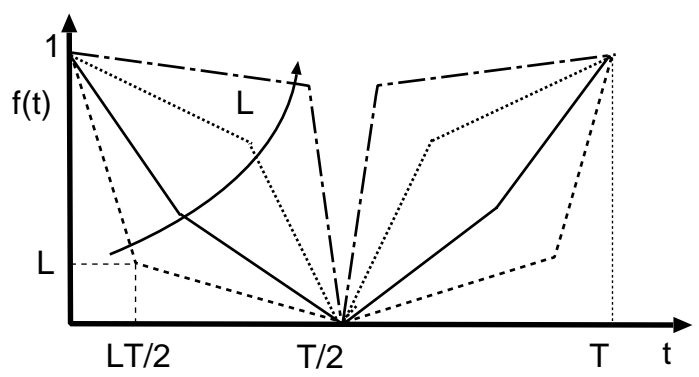

Figure 3: Synthetic traffic pattern.

Fig. 3 and defined by

$$
f(t)= \begin{cases}\frac{L-1}{L} \frac{2 t}{T}+1 & 0 \leq t<\frac{T}{2} L \\ \frac{L}{L-1}\left(\frac{2 t}{T}-1\right) & \frac{T}{2} L \leq t \leq \frac{T}{2}\end{cases}
$$

with $L \in[0,1]$. The parameter $L$ defines the position of the curve knee: the knee is in $(L T / 2, L)$; for $L=1 / 2$ the curve is made of just two segments: one for decreasing traffic and one for increasing traffic.

We start by analyzing the case of one low-power network configuration, $N=1$, that alternates to the normal full-capacity configuration. When $L>1 / 2$, the maximum energy saving is reached for two values of $\tau$,

$$
\tau^{*}=T / 2 \frac{3 L-1}{2 L} \quad \text { and } \quad \tau^{*}=T / 4
$$

When $L \leq 1 / 2$, the maximum occurs at the curve knee, that is for

$$
\tau^{*}=\frac{T L}{2}
$$

When two low-power configurations are allowed, i.e., $N=2$, the maximum saving is achieved for $\left(\tau_{1}^{*}, \tau_{2}^{*}\right)$ with,

$$
\left(\tau_{1}^{*}, \tau_{2}^{*}\right)= \begin{cases}\left(\frac{T}{4} \frac{L(3 L-1)}{2 L^{2}-1 / 2(L-1)^{2}}, \frac{T}{2} \frac{L(3 L-1)}{2 L^{2}-1 / 2(L-1)^{2}}\right) & \text { if } L>1 / 3 \\ \left(\frac{T}{2} L, \frac{T}{4}(L+1)\right) & \text { otherwise }\end{cases}
$$

For a case in which the BS consumption is independent of the traffic (similar to existing equipment), i.e., $W_{T}=0$ in (5), Fig. 4 shows, in percentage, the maximum network saving 


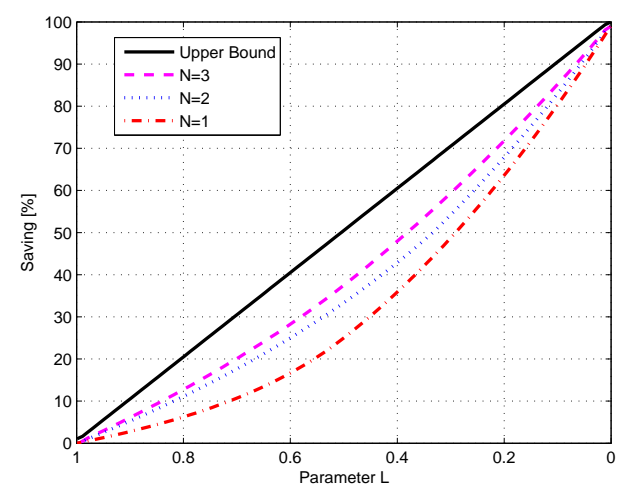

Figure 4: Synthetic traffic pattern: maximum achievable saving for various number of network configurations versus the parameter $L$.

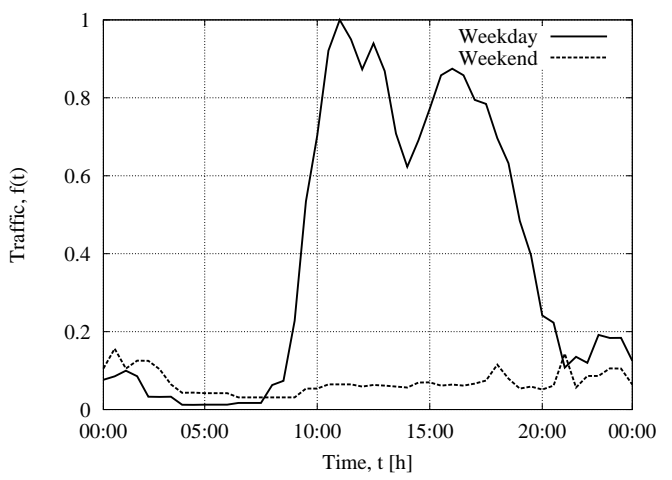

Figure 5: Business cell: weekday and weekend traffic profiles.

versus $L$ for various values of $N$; the upper bound is also reported. Clearly, the saving increases with $N$, reaching the upper bound for $N \rightarrow \infty$. Values of $N$ equal to 2 or 3 are enough to achieve saving that is close to the upper bound. Higher values of $N$ bring small additional improvements only, while introducing higher complexity in network management. By computing the difference between the maximum achievable saving in the case of two low-power configurations and one only, we found that the saving increase is at most $8 \%$, suggesting that the use of two configurations instead of one only does improve the maximum achievable saving, but to a limited extent.

\subsection{Measured Traffic patterns}

We now consider traffic profiles measured from the network of an anonymized cellular operator. In particular, we consider traffic profiles taken from two individual urban cells with different user types: one cell refers to a business area, and the other one to an area that is mainly residential. Moreover, for each of these cells, we consider two profiles: the weekday profile is chosen as the average of the weekday profiles collected during a week; the weekend profile is an average of the two weekend days of the same week. The traffic profiles are reported in Figs. 5 and 6 . Profiles are normalized to the weekday peak value, that occurs around 11am for the business area, and 


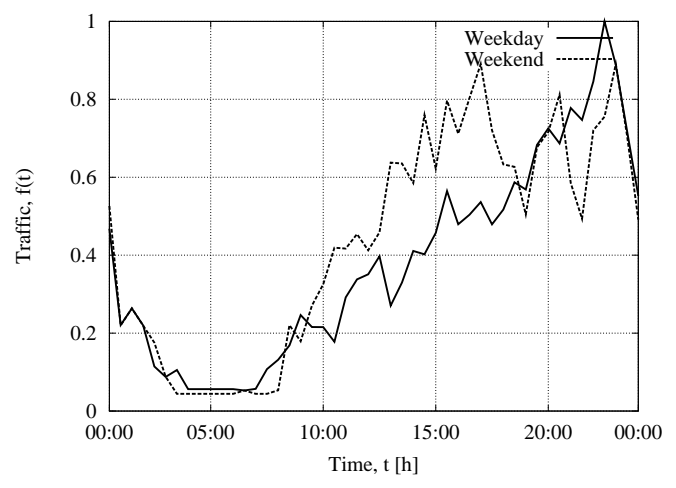

Figure 6: Residential cell: weekday and weekend traffic profiles.

in the evening for the residential area. Clearly, two completely different trends characterize the two areas: traffic is concentrated during the working hours of the weekdays for the business area, while traffic is higher during the evening for the residential area, where the difference between weekdays and weekends is marginal. However, for both profiles, traffic is very low from late night to early morning, i.e., from 2.30am to 7.30am approximately. The transitions from peak to off-peak and vice-versa are extremely steep in the business weekday profile, while they are slow in the residential area. As expected, profiles are very specific of given areas and can vary quite remarkably. However, from the set of real measurements we analyzed, we found that, given a certain type of area (residential or business), all traffic profiles relative to that area are characterized by a very similar trend. This suggests that the sleep scheme should be planned based on the type of the urban area.

Table 1 shows the maximum achievable savings under different sleep schemes. We also consider different power consumption models, by varying the values of $W_{L P I}, W_{0}$ and $W_{T}$. We observe that saving is higher when $W_{0}$ equals the maximum power consumption (i.e., the normalized value is equal to one), and the consumptions $W_{L P I}$ and $W_{T}$ are zero. Obviously, saving decreases as $W_{T}$ increases (and $W_{0}$ decreases accordingly), and when the power consumption in LPI mode increases.

Among the considered profiles, the largest saving is achieved with the business weekend profile, since traffic is extremely low during the whole day. As expected, saving increases with $N$ for all profiles ${ }^{2}$. Again, as $N$ increases, the additional saving with respect to the single low-power configuration case is limited, with some differences between the business and residential cases. In the case of the business weekday profile, with very steep transitions from off-peak to peak traffic, one low-power network configuration, $N=1$, is already very effective and only marginal improvements are achieved with higher values of $N$. For the residential area case, improvements with $N$ are larger. This difference again suggests that the choice of the sleep scheme should be tailored to the traffic profiles and the type of area.

\subsection{Sleep Modes with Deployment Constraints}

While in the previous section we derived the optimal energy saving considering the shape of function $f(t)$ only, in real cases it is not possible to put to sleep any fraction $1-x$ of the

\footnotetext{
${ }^{2}$ Note that, we suppose that an operator may apply multiple low-power network configurations only during sufficiently large time intervals (e.g., during night), and does not apply any sleep scheme during short intervals of low traffic, i.e., when traffic decreases for few minutes only.
} 
Table 1: Measured traffic patterns: maximum achievable saving for various number of network configurations

\begin{tabular}{|c|c|c|c|c|c|}
\hline Power Consumption Model & Network configuration & $\begin{array}{c}S[\%] \\
\text { Business WE }\end{array}$ & $\begin{array}{c}S[\%] \\
\text { Business WD }\end{array}$ & $\begin{array}{c}S[\%] \\
\text { Residential WE }\end{array}$ & $\begin{array}{c}S[\%] \\
\text { Residential WD }\end{array}$ \\
\hline$W_{L P I}=0.0 \quad W_{0}=1.0 \quad W_{T}=0.0$ & $\begin{array}{c}\text { Upper Bound } \\
N=3 \\
N=2 \\
N=1\end{array}$ & $\begin{array}{l}91.40 \\
89.85 \\
89.28 \\
84.30\end{array}$ & $\begin{array}{l}61.86 \\
50.96 \\
46.57 \\
42.01\end{array}$ & $\begin{array}{l}50.10 \\
40.06 \\
34.55 \\
26.61\end{array}$ & $\begin{array}{l}59.90 \\
49.21 \\
44.91 \\
33.90\end{array}$ \\
\hline$W_{L P I}=0.1 \quad W_{0}=0.8 W_{T}=0.1$ & $\begin{array}{c}\text { Upper Bound } \\
N=3 \\
N=2 \\
N=1\end{array}$ & $\begin{array}{l}80.46 \\
79.10 \\
78.62 \\
74.21\end{array}$ & $\begin{array}{l}52.68 \\
43.39 \\
39.65 \\
35.77\end{array}$ & $\begin{array}{l}42.16 \\
33.71 \\
29.07 \\
22.40\end{array}$ & $\begin{array}{l}50.90 \\
41.82 \\
38.16 \\
28.81\end{array}$ \\
\hline$W_{L P I}=0.0 \quad W_{0}=0.6 \quad W_{T}=0.4$ & $\begin{array}{c}\text { Upper Bound } \\
N=3 \\
N=2 \\
N=1\end{array}$ & $\begin{array}{l}86.38 \\
84.92 \\
84.38 \\
79.67\end{array}$ & $\begin{array}{l}48.99 \\
40.35 \\
36.88 \\
33.27\end{array}$ & $\begin{array}{l}37.45 \\
29.94 \\
25.82 \\
19.90\end{array}$ & $\begin{array}{l}46.97 \\
38.58 \\
35.21 \\
26.58\end{array}$ \\
\hline$W_{L P I}=0.1 \quad W_{0}=0.4 W_{T}=0.5$ & $\begin{array}{c}\text { Upper Bound } \\
N=3 \\
N=2 \\
N=1\end{array}$ & $\begin{array}{l}67.26 \\
66.12 \\
65.70 \\
62.04\end{array}$ & $\begin{array}{l}35.50 \\
29.24 \\
26.72 \\
24.10\end{array}$ & $\begin{array}{l}26.60 \\
21.27 \\
18.34 \\
14.13\end{array}$ & $\begin{array}{l}33.91 \\
27.86 \\
25.42 \\
19.19\end{array}$ \\
\hline
\end{tabular}

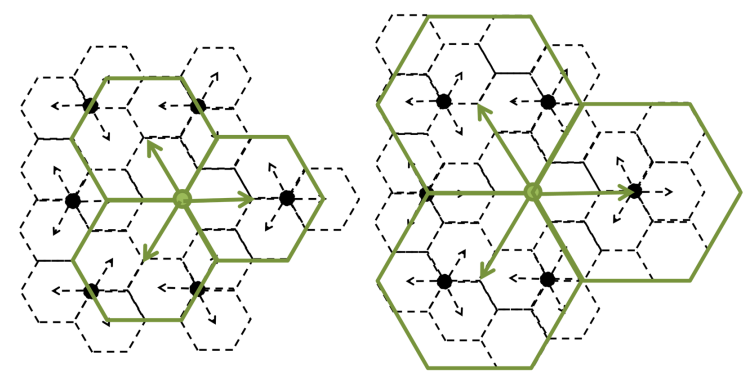

Figure 7: Hexagonal three-sectorial configuration: 3 cells being put to sleep out of 4 (left) and 8 out of 9 (right).

cells, since the access network geometry and the actual site positioning constrain the fraction of sleeping cells to only a few specific values. In this section, we start by focusing on two simple abstract regular cell layouts, and we evaluate, taking into account the deployment constraints, the actual achievable saving.

Two frequently considered cellular network configurations are the following:

- Hexagonal cells with tri-sectorial antennas: the BS is at a vertex of the cell, during low traffic periods the cell expands so as to cover the equivalent of 4 or 9 cells. This scheme results in 3 cells being put to sleep out of 4 or 8 out of 9 , as sketched in Fig. 7 .

- Manhattan layout: cells form a grid structure; this case is typical of streets in a urban scenario. Many sleep schemes are possible, depending on whether the cell is extended along a line or in an omnidirectional fashion, creating square-shaped cells. For the linear case, we consider the schemes represented in the top part of Fig. $8(1 / 2,2 / 3$ and $3 / 4$ cells are put to sleep); for the squared case, as represented in the bottom part of the same figure, we consider schemes leading to 3 out of 4 and 8 out of 9 sleeping cells.

Under the constraints imposed by the regular cell layouts described above, we consider both the synthetic and measured traffic profiles presented in the previous section. Fig. 9 reports the percentage saving versus the parameter $L$ of the synthetic traffic profile, obtained when two low-power network configurations are used. For completeness, the saving upper bound and the maximum saving achievable with $N=2$ are reported as well. Several cases are considered; for example, the case labeled ' $1 / 2-2 / 3$ ' means that one out of two cells are put to sleep at time 

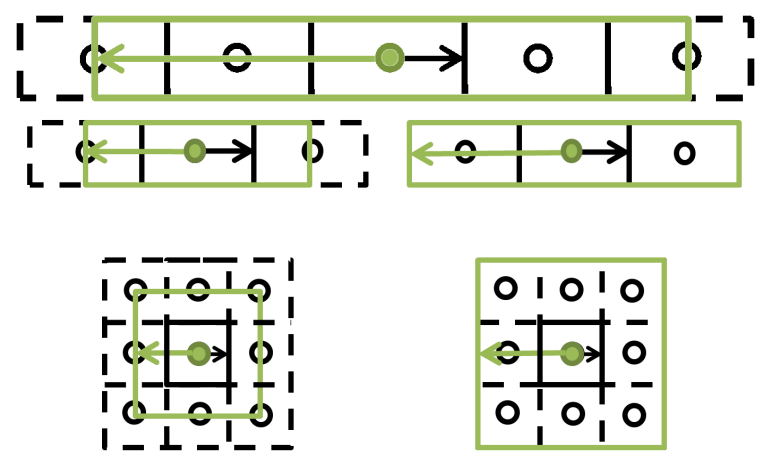

Figure 8: Manhattan configurations: linear (top) and squared (bottom).

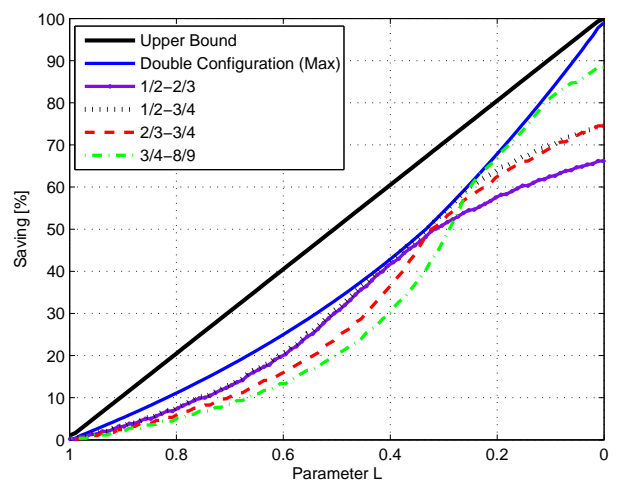

Figure 9: Two low traffic network configurations: network saving versus the parameter $L$ for the synthetic traffic profile.

instant $\tau_{1}$ and two out of three are in sleep mode from time instant $\tau_{2}$. For small values of $L$ (right part of the curves) the largest saving is obtained by putting into sleep mode the largest fraction of cells (configuration 8/9). These values of $L$ correspond to cases in which the transient from the peak to the off-peak traffic is short (steep decrease) and it is convenient to put to sleep a larger number of cells for a (slightly) shorter time. However, the saving rapidly decreases as $L$ increases, and the schemes that correspond to put to sleep a smaller number of cells, such as $1 / 2$ or $2 / 3$, become more convenient.

Consider now the measured traffic profiles of the business area. Fig. 10 reports the network saving that can be achieved with two low-power network configurations, considering the weekday traffic pattern. The graph, with its level curves, shows the saving achievable when the first configuration is entered at $\tau_{1}$ and the second one at $\tau_{2}$. Observe that, by the definition of $\tau_{i}$, the white area for which $\tau_{1}>\tau_{2}$ corresponds to non admissible points. The markers localize the cases possible with regular topologies. Saving is maximized when the first configuration occurs in the evening, and the second is during night. The strange behavior of the curves corresponding to the vertical slice around lunch time is due to the corresponding gap in the traffic profile, see Fig. 5. Interestingly, regular topologies, identified by the markers in the figure, achieve good saving, pretty close to the maximum possible. This suggests that, even in presence of some topological and physical layout constraints, sleep schemes can be quite effective. 


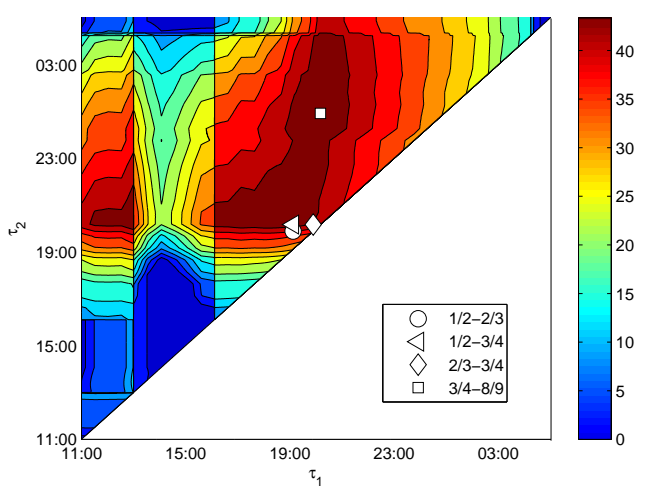

Figure 10: Business cell - weekday profile: network saving with two low traffic network configurations.

\section{Heterogeneous Networks}

In the previous section, we have considered homogeneous networks in which all BSs are characterized by the same power consumption and the same traffic load, and cells are equivalent and interchangeable in terms of coverage, so that any number of cells can be put into sleep mode while the remaining active cells guarantee coverage. We now consider the case of heterogeneous networks, i.e., networks in which cells of different size and load coexist (possibly covered by BSs of different technologies). In particular, we consider a scenario in which an umbrella (macro) cell provides coverage over an area, and $K$ micro-cells are deployed to provide additional capacity. To save energy, micro-cells can be put to sleep when their traffic is low and can be carried by the macro-cell; in this case, their traffic cannot be carried by the other micro-cells due to coverage limits.

As before, we assume that the traffic profile $f(t)$ of the umbrella cell is decreasing with $t$ and is symmetric around $T / 2$. The micro-cells have the same traffic profile shape as the macro-cell, since this is given by the typical human behavior that is assumed to be uniform in a given area; however, based on the cell size and user density, the shape can be scaled of a given factor, i.e., micro-cell $i$ supports a traffic that is $\alpha_{i} f(t)$. We assume that micro-cell $i$ consumes an amount of power equal to

$$
P^{(i)}(t)=W_{L P I}^{(i)}+W_{0}^{(i)}+W_{T}^{(i)} \alpha_{i} f(t)
$$

while the macro-cell consumes

$$
P^{(M)}(t)=W_{L P I}^{(M)}+W_{0}^{(M)}+W_{T}^{(M)} f(t)
$$

In the case of homogeneous networks, a low-power network configuration $\Phi$ was defined by the fraction of active cells $x$ and the corresponding smallest instant $\tau$ in which the load constraint (2) was satisfied. Here, in the heterogeneous case, we define a low-power configuration by specifying the active/sleep state, micro-cell by micro-cell. In particular, a configuration $\Psi$ can be represented through an indicating function, $I^{(\Psi)}(k)$ with $k=1, \cdots, K$, that defines the state of the micro-cell $k$, that can be either sleeping or active,

$$
I^{(\Psi)}(k)= \begin{cases}1 & \text { if micro-cell } k \text { is sleeping } \\ 0 & \text { if micro-cell } k \text { is active }\end{cases}
$$


The configuration $\Psi$ is feasible at time $t$ if the following load constraint condition holds,

$$
\left(1+\sum_{k=1}^{K} \alpha_{k} I^{(\Psi)}(k)\right) f(t)<1
$$

This condition imposes that the load in the macro-cell does not exceed the maximum allowable load, namely 1; and that the macro-cell is receiving the traffic of all the micro-cells that are in sleep mode, i.e., for which $I^{(\Psi)}(k)=1$. Assuming, as before, that $f(t)$ is symmetric and decreasing in $[0, T / 2]$, the scheme $\Psi$ becomes feasible at time $\tau$, with,

$$
\tau=f^{-1}\left(\frac{1}{1+\sum_{k=1}^{K} \alpha_{k} I^{(\Psi)}(k)}\right)
$$

Putting to sleep micro-cell $k$ at time $t$ is convenient in terms of energy consumption when the additional cost that the macro-cell has to sustain to carry the traffic of micro-cell $k$ is smaller than the saving achieved by putting micro-cell $k$ into sleep mode; i.e., when the following saving constraint holds,

$$
W_{0}^{(k)}+W_{T}^{(k)} \alpha_{k} f(t) \geq W_{T}^{(M)} \alpha_{k} f(t)
$$

We define, then, a scheme $\Psi$ to be convenient at time $t$ if (23) holds for every micro-cell $k$ in sleep mode. When $\Psi$ is applied, the power saving is equal to,

$$
S^{(\Psi)}(t)=\sum_{k=1}^{K}\left[W_{0}^{(k)}+\left(W_{T}^{(k)}-W_{T}^{(M)}\right) \alpha_{k} f(t)\right] I^{(\Psi)}(k)
$$

To find the optimal multiple low-power configuration sleep scheme, we first define the set of all possible configurations, $\mathcal{C}$. The set $\mathcal{C}$ contains $2^{K}$ elements that correspond to all possible combinations of any micro-cell being either active or sleeping, $\mathcal{C}=\left\{\Psi_{i}\right\}$ with $i=0, \cdots, 2^{K}$. At time $t$, the set of the feasible and convenient configurations is defined by those configurations $\Psi_{i}$ that, at $t$, satisfy both the load constraint (21) and the saving constraints (23),

$$
\begin{aligned}
& \mathcal{C}(t) \subset \mathcal{C} \text {, with } \\
& \mathcal{C}(t)=\left\{\begin{array}{l|l}
\Psi_{i} & \left.\left(1+\sum_{k=1}^{K} \alpha_{k} I^{\left(\Psi_{i}\right)}(k)\right) f(t)<1\right\} \cap \\
\Psi_{i} & \forall k, I^{\left(\Psi_{i}\right)}(k)\left[W_{0}^{(k)}+\left(W_{T}^{(k)}-W_{T}^{(M)}\right) \alpha_{k} f(t)\right] \geq 0
\end{array}\right.
\end{aligned}
$$

Among the configurations in $\mathcal{C}(t)$, an optimal choice, $\Psi^{*}(t) \in \mathcal{S}(t)$, is given by one of the configurations that maximizes the saving in (24),

$$
\Psi^{*}(t)=\max _{\Psi_{i} \in \mathcal{C}(t)} S^{(\Psi)}(t)
$$

We focus now on the (realistic) case in which the cost to carry a unit of traffic in the macrocell, $W_{T}^{(M)}$ is larger than the costs to carry the same amount of traffic in the micro-cells, $W_{T}^{(k)}$. Indeed, the larger transmission power makes this happens most of the time [24].

This assumption means that in (24) the terms $W_{T}^{(k)}-W_{T}^{(M)}$ are negative, and the larger the traffic $\alpha_{k} f(t)$ is, the smaller the saving is.

Lemma 1: Under the two following conditions,

1. all micro-cells have the same power consumption model, i.e., $W_{L P I}^{(k)}=W_{L P I}, W_{0}^{(k)}=W_{0}$ and $W_{T}^{(k)}=W_{T}$; 
2. the cost to carry a unit of traffic through the macro-cell is higher than through the microcell, i.e., $W_{T}^{(M)}>W_{T}$;

the "least-loaded" policy, consisting in putting the micro-cells into sleep mode in reverse order w.r.t. their load, i.e., from the least loaded to the most loaded, is optimal in terms of the achieved saving.

Proof. Consider a configuration $\Psi_{i}$. The term $f(t) \sum_{k=1}^{K} \alpha_{k} I^{\left(\Psi_{i}\right)}(k)$ represents the traffic increment that the macro-cell undergoes when $\Psi_{i}$ is applied; where $\alpha_{k} f(t)$ is the contribution to traffic due to micro-cell $k$ going to sleep mode. Now, since $f(t)$ is monotonically decreasing in $[0, T / 2]$, the time $\tau_{i}$ at which $\Psi_{i}$ can be applied depends on this traffic increment; considering two configurations $\Psi_{i}$ and $\Psi_{j}$,

$$
\tau_{i}<\tau_{j} \quad \text { if } \quad \sum_{k=1}^{K} \alpha_{k} I^{\left(\Psi_{i}\right)}(k)<\sum_{k=1}^{K} \alpha_{k} I^{\left(\Psi_{j}\right)}(k)
$$

That is, the time order in which the configurations become feasible (i.e., satisfy the load constraint) is according to increasing values of the total traffic added to the macro-cell.

Denote by $\phi_{i}$ the time at which putting to sleep micro-cell $i$ becomes convenient; from (23),

$$
\phi_{i}=f^{-1}\left(\frac{W_{0}}{\alpha_{i}\left(W_{T}^{(M)}-W_{T}\right)}\right)
$$

Since $f(t)$ is monotonically decreasing, the times $\phi_{i}$ are ordered according to increasing values of the individual micro-cell load, $\alpha_{i}$, that is:

$$
\phi_{i}<\phi_{j} \quad \text { if } \quad \alpha_{i}<\alpha_{j}
$$

Now, consider the set $A_{V} \subset \mathcal{C}$ of all the configurations $\Psi_{i}$ corresponding to $V$ micro-cells in sleep mode,

$$
A_{V}=\left\{\Psi_{i} \mid \sum_{k=1}^{K} I^{\left(\Psi_{i}\right)}(k)=V\right\}
$$

Among these, the scheme $\Psi_{V}$ that saves the most, corresponds to putting to sleep the $V$ least loaded cells. Indeed, from (24), the saving is

$$
S^{\left(\Psi_{V}\right)}=V W_{0}+\sum_{k=1}^{K}\left(W_{T}-W_{T}^{(M)}\right) \alpha_{k} f(t) I^{\left(\Psi_{V}\right)}(k)
$$

and, since the second term is negative, due to $W_{T}^{(M)}>W_{T}$, the saving is maximized if the amount of traffic of the sleeping cells is smallest.

Moreover, among the schemes in $A_{V}, \Psi_{V}$ is also the one that becomes feasible at the earliest time, since according to (27), the micro-cells can be put to sleep in the order of the amount of carried load.

When $\Psi_{V}$ satisfies the constraint (23), its saving is larger than the best scheme of $A_{V-1}$, that is $\Psi_{V-1}$ : i.e., $S^{\left(\Psi_{V}\right)}>S^{\left(\Psi_{V-1}\right)}$ because the contribution to saving given by each micro-cell $k$ that is sleeping is positive:

$$
W_{0}+\left(W_{T}-W_{T}^{(M)}\right) \alpha_{k} f(t)>0
$$


and the saving $S^{\left(\Psi_{V}\right)}$ is composed of the sum of the same savings of $\Psi_{V-1}$ plus a positive term, corresponding to the additional cell that is sleeping in $\Psi_{V}$ w.r.t. $\Psi_{V-1}$.

Denote by $t_{V}$ the time instant in which $\Psi_{V}$ becomes feasible and convenient. By definition of $t_{V}$, in the interval between $t_{V}$ and $t_{V+1}$, no configuration can save more than $\Psi_{V}$, so that in the interval $\left[t_{V}, t_{V+1}\right]$ the configuration $\Psi_{V}$ is optimum, in the sense that it achieves the maximum possible saving.

By extending this reasoning to the other time intervals, we conclude that putting to sleep micro BS from the least loaded to the most loaded, leads to the maximum saving.

\subsection{Case Study}

In the following, we finally show how the previous results can be applied to a realistic cell deployment.

We consider a portion of the central area of the city of Munich, in Germany, which corresponds to a square of $800 \times 800 \mathrm{~m}$, comprising 1 macro-cell, 8 micro-cells, and 10 femto-cells. Femto-cells are deployed to provide additional capacity during peak hours in indoor environments. However, we do not consider them in the sleep schemes, since they consume a negligible amount of power. The micro-cells are served by isotropic antennas, each with transmission power of $1 \mathrm{~W}$, while the macro-cell has a tri-sectorial antenna with $40 \mathrm{~W}$ emitted power. We assume that the total power consumption of the macro-cell is seven times higher than the one of a micro-cell [25]. Fig. 11 presents a map of the considered area, together with a side view (at the bottom of the figure).

The area coverage is computed from the signal strength received on the users' pilot channel. To estimate the channel conditions, i.e., the path losses, we use the results of a tool developed by Alcatel-Lucent, called Wireless System Engineering (WiSE) [26], that is based on ray-tracing techniques. We refer the reader to [27] for further details on users' coverage computation.

The network is planned assuming that in the coverage areas of the micro-cells, the users density is 5 times higher than in the remaining area. As traffic profile, we consider the weekday profiles of either the business or the residential areas, see Figs. 5 and 6 . Moreover, we assume that at the peak traffic hour, the most loaded cell carries a normalized traffic load equal to 1 . During low traffic periods, micro-cells enter sleep mode, and the macro-cell acts as an umbrella cell which is never switched off. We assume that the macro-cell can guarantee full coverage, even when all the other cells are put into sleep mode.

Table 2 summarizes the network saving obtained under different schemes, for both the considered profiles, and for different power consumption models. As already noted in Section 3, the highest saving is achieved when the power consumption $W_{0}$ is maximum and the power consumed in LPI state is zero, with saving that slightly decreases as $W_{T}$ increases. Moreover, the increase of $W_{L P I}$ makes the sleep mode scheme less convenient.

Saving of the order of $15-25 \%$ can be achieved with one low-power network configuration. The saving increases significantly with two low-power configurations (up to $32 \%$ ), while the saving increment is marginal as the number of configurations further increases. Note that, in the case of one low-power configuration, the savings achievable with the business traffic profile are higher, due to the higher steepness of the transients; the maximum savings are, instead, comparable for the two traffic profiles.

Finally, Figs. 12 and 13 show the number of active micro BSs versus time, considering the weekday traffic profiles: the cases of one, two, three low-power configurations, are reported. For completeness, the curve obtained with the Least-Loaded policy is also shown (label 'Maximum'): this represents a lower bound on the minimum number of active BSs, and corresponds to the maximum achievable saving. 


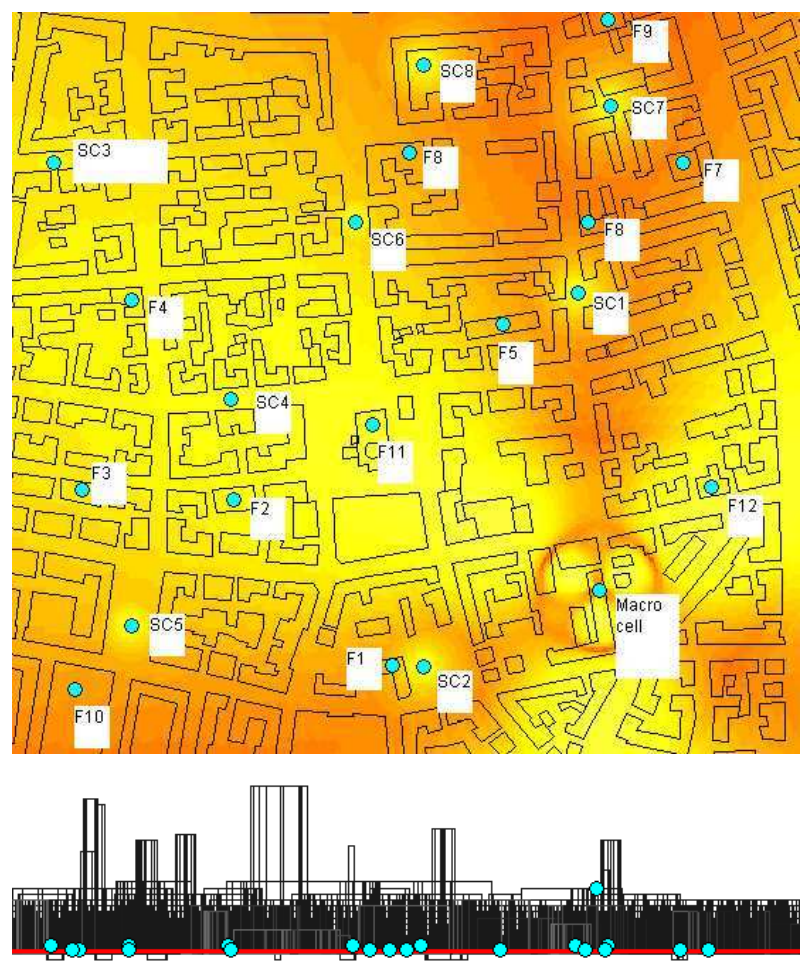

Figure 11: Case study: Map with cell identifiers $(\mathrm{SC}=$ micro cell). Aerial view (top) and side view (bottom).

\section{Conclusions}

In this paper we investigated the energy saving that can be achieved in cellular access networks by optimizing the use of sleep modes according to daily traffic variations.

By assuming that, as is usually the case in dense urban environments, when a cell is in sleep mode, coverage can be filled by its neighbors, we derived expressions for the optimal energy saving when the network can move among $N$ different low-power network configurations, and an expression for a theoretical upper bound of saving. Our derivation proves that energy savings, as well as the optimal choice of the periods in which different low-power configurations should be adopted, are functions of the daily traffic patterns. Thus, the first main insight deriving from this work is that the daily traffic pattern plays a central role in the design of dynamic network planning schemes that adopt sleep modes.

The numerical results we presented, derived for many cell layouts, traffic patterns, and power consumption models, provide several additional interesting insights. First of all, for the considered real traffic patterns, savings are quite significant: they reach $90 \%$ in the case of weekend traffic in business areas, and are of the order of $30-40 \%$ in other cases. This is an important signal indicating that sleep modes can indeed be a useful tool for energy-efficient networking. Second, we have shown that significant savings can be achieved with only one low-power network configuration per day, while the benefit of multiple configurations is minor. This is especially true in the case in which the traffic profile has a steep transition from the off-peak hours to on-peak hours, 
Table 2: Case Study: savings with different network configurations

\begin{tabular}{|c|c|c|c|}
\hline Power Consumption Model & Network configuration & $\begin{array}{c}S[\%] \\
\text { Business weekday }\end{array}$ & $\begin{array}{c}S[\%] \\
\text { Residential weekday }\end{array}$ \\
\hline \multirow{4}{*}{$W_{L P I}=0.0 W_{0}=1.0 W_{T}=0.0$} & Single (7/9) & 26.39 & 19.73 \\
\hline & Double $(4 / 9)-(7 / 9)$ & 31.96 & 32.16 \\
\hline & Triple $(2 / 9)-(4 / 9)-(7 / 9)$ & 34.64 & 33.43 \\
\hline & Maximum (Least-Loaded) & 38.27 & 38.79 \\
\hline \multirow{4}{*}{$W_{L P I}=0.1 \quad W_{0}=0.8 W_{T}=0.1$} & Single $(7 / 9)$ & 23.18 & 17.24 \\
\hline & Double $(4 / 9)-(7 / 9)$ & 27.84 & 27.73 \\
\hline & Triple $(2 / 9)-(4 / 9)-(7 / 9)$ & 30.06 & 28.78 \\
\hline & Maximum (Least-Loaded) & 33.16 & 33.30 \\
\hline \multirow{4}{*}{$W_{L P I}=0.0 \quad W_{0}=0.6 \quad W_{T}=0.4$} & Single $(7 / 9)$ & 24.69 & 17.92 \\
\hline & Double $(4 / 9)-(7 / 9)$ & 28.73 & 27.31 \\
\hline & Triple $(2 / 9)-(4 / 9)-(7 / 9)$ & 30.05 & 28.18 \\
\hline & Maximum (Least-Loaded) & 33.55 & 32.21 \\
\hline \multirow{4}{*}{$W_{L P I}=0.1 W_{0}=0.4 W_{T}=0.5$} & Single $(7 / 9)$ & 18.99 & 13.53 \\
\hline & Double $(4 / 9)-(7 / 9)$ & 21.71 & 20.00 \\
\hline & Triple $(2 / 9)-(4 / 9)-(7 / 9)$ & 22.94 & 20.59 \\
\hline & Maximum (Least-Loaded) & 25.10 & 23.27 \\
\hline
\end{tabular}

like in business areas during weekdays. This is also an important message, because it shows that most of the gains can be obtained with limited effort on the side of network management. Third, savings can be strongly influenced by the different power consumption components of a BS. Indeed, sleep modes are more effective when the power necessary to carry zero traffic is high, and both the power consumption in LPI mode and the power proportional to the traffic are low.

Finally, we have also proved that in presence of deployment of BSs for additional capacity provisioning, the optimal order in which the BSs should enter sleep mode, i.e. the order that jointly maximizes energy saving and minimizes the number of BS transients, consists in putting cells to sleep according to increasing values of their load. This too, is a relevant result for network management.

Our results provide a tangible incentive for cellular network operators to implement sleep modes in their networks.

\section{Acknowledgement}

The authors wish to thank Alberto Conte and Afef Feki of Alcatel-Lucent Bells Labs for providing data about the real BS deployment and coverage in downtown Munich. The research leading to these results has received funding from the European Union Seventh Framework Programme (FP7/2007-2013) under grant agreement n. 257740 (Network of Excellence TREND).

\section{References}

[1] M. Ajmone Marsan, L. Chiaraviglio, D. Ciullo, M. Meo, Optimal Energy Savings in Cellular Access Networks, GreenComm'09 - 1st International Workshop on Green Communications, Dresden, Germany, June 2009.

[2] M. Ajmone Marsan, L. Chiaraviglio, D. Ciullo, M. Meo, Multiple Daily Base Station SwitchOffs in Cellular Networks, accepted at the Fourth International Conference on Communica- 


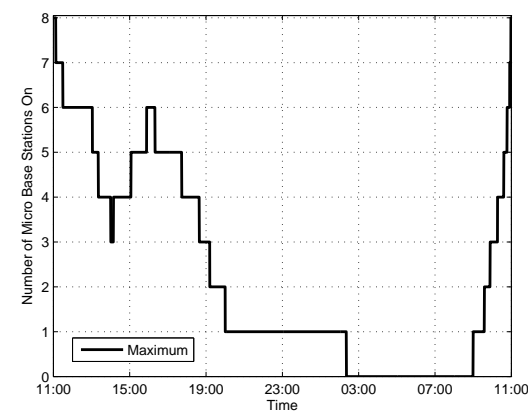

(a) Maximum

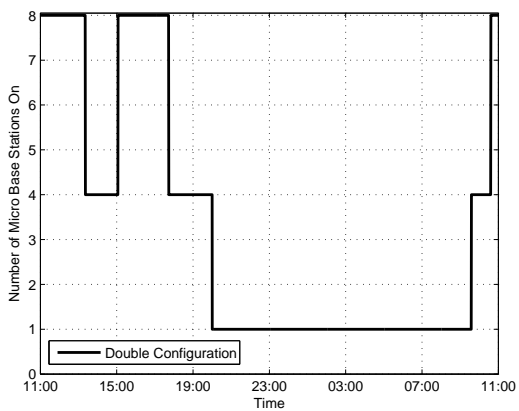

(c) Double

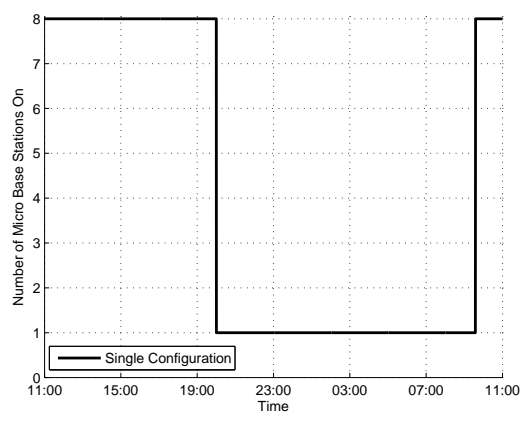

(b) Single

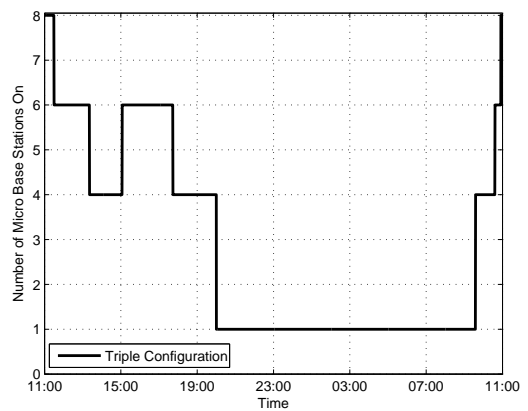

(d) Triple

Figure 12: Business weekday: number of active micro BSs versus time for different network configurations.

tions and Electronics (ICCE'12), Hue, Vietnam, August 2012. Technical report available at http://www.telematica.polito.it/chiaraviglio/papers/

MultipleSwitchOffsCellular.pdf.

[3] A. Giessler, J. Haenle, A. Koenig, E. Pade, Free buffer allocation: An investigation by simulation, Computer Networks, Vol.2, n.3, July 1978, pp. 191-208.

[4] L. Kleinrock, Power and Deterministic Rules of Thumb for Probabilistic Problems in Computer Communications, ICC 79, Boston, MA, USA, June 1979.

[5] M. Gupta, S. Singh, Greening of the Internet, ACM SIGCOMM 2003, Karlsruhe, Germany, August 2003.

[6] TREND Project, http://www.fp7-trend.eu.

[7] K. Son, B. Krishnamachari, SpeedBalance: Speed-Scaling-Aware Optimal Load Balancing for Green Cellular Networks, IEEE INFOCOM Mini-conference 2012, Orlando, FL, USA, March, 2012.

[8] O. Arnold, F. Richter, G. Fettweis, and O. Blume, Power consumption modeling of different base station types in heterogeneous cellular networks, in Proc. of 19th Future Network and MobileSummit, 2010. 


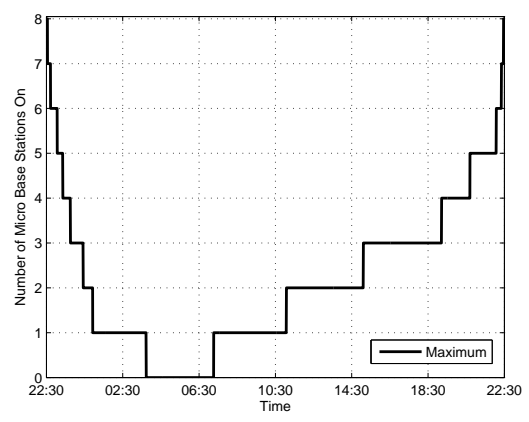

(a) Maximum

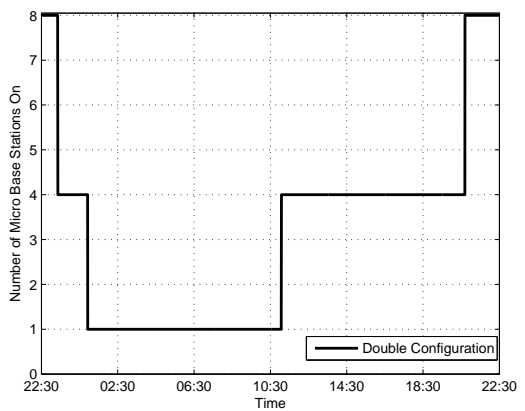

(c) Double

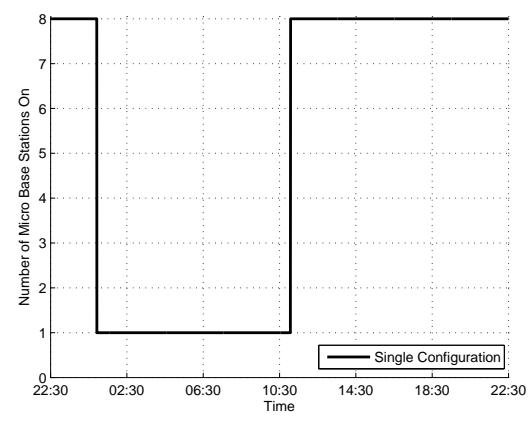

(b) Single

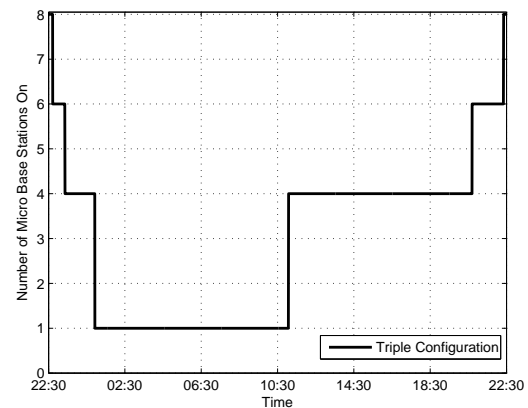

(d) Triple

Figure 13: Residential weekday: number of active micro BSs versus time for different network configurations.

[9] J. Lorincz, T. Garma, G. Petrovic, Measurements and Modelling of Base Station Power Consumption under Real Traffic Loads, Sensors, Vol. 12, pp. 4281-4310.

[10] J.T. Louhi, Energy efficiency of modern cellular base stations, INTELEC 2007, Rome, Italy, September-October 2007.

[11] H. O. Scheck, J. Louhi, Energy Efficiency of Cellular Networks, W-GREEN 2008, Lapland, Finland, September 2008.

[12] Global Action Plan, An inefficient truth, http://www.globalactionplan.org.uk/, Global Action Plan Rep., 2007.

[13] M. Hodes, Energy and power conversion: A telecommunication hardware vendor's perspective, http://www.peig.ie/pdfs/ALCATE 1.PPT, Power Electronics Industry Group, 2007.

[14] Bi-annual Report November 2010, Green Power for Mobile, GSMA. Available: http://www.gsmworld.com/our-work/mobile

planet/green_power_for_mobile/renewable_energy_networks.htm.

[15] H. Claussen, L. T. W Ho, and F. Pivit, Effects of joint macrocell and residential picocell deployment on the network energy efficiency, IEEE 19th International Symposium on Personal, Indoor and Mobile Radio Communications (PIMRC), 2008, Cannes, France, September 2008. 
[16] Z. Niu, Y. Wu, J. Gong, Z. Yang, Cell zooming for cost-efficient green cellular networks, IEEE Communication Magazine, Vol. 48, n. 11, pp. 74-79, November 2010.

[17] L. Chiaraviglio, D. Ciullo, M. Meo, M. Ajmone Marsan, Energy-Aware UMTS Access Networks, W-GREEN 2008, Lapland, Finland, September 2008.

[18] M. Ajmone Marsan, L. Chiaraviglio, D. Ciullo, M. Meo, Energy-Efficient Management of UMTS Access Networks, ITC 21 - 21st International Teletraffic Congress, Paris, France, September 2009.

[19] E. Oh, B. Krishnamachari, X. Liu, Z. Niu, Toward dynamic energy efficient operation of cellular network infrastructure, IEEE Communication magazine, Vol. 49, n. 6, pp. 56-61, June 2011.

[20] K. Son, H. Kim, Y. Yi and B. Krishnamachari, Base Station Operation and User Association Mechanisms for Energy-Delay Tradeoffs in Green Cellular Networks, IEEE Journal on Selected Area in Communications: Special Issue on Energy-Efficient Wireless Communications, Vol. 29, No. 8, pp. 1525 - 1536, September 2011.

[21] C. Peng, S. B. Lee, S. Lu, H. Luo, H. Li, Traffic-Driven Power Saving in Operational $3 G$ Cellular Networks, ACM MobiCom 2011, Las Vegas, Nevada, USA, September 2011.

[22] L.i Saker, S. E. Elayoubi, Sleep mode implementation issues in green base stations, PIMRC 2010, Istanbul, Turkey, September 2010.

[23] M. Ajmone Marsan, M. Meo, Energy Efficient Wireless Internet Access with Cooperative Cellular Networks, Computer Networks, 2011, Vol. 55,, No. 2, pp. 386 - 398.

[24] G. Auer et al., How much Energy is needed to run a Wireless Network?, IEEE Wireless Commun. Mag., vol. 18, no. 5, pp. 40ї $\frac{1}{2} 49$, October 2011.

[25] G. Auer, V. Giannini, I. Godor, P. Skillermark, M. Olsson, M. A. Imran, D. Sabella, M. J. Gonzalez., C. Desset, O. Blume, Cellular Energy Efficiency Evaluation Framework, GreeNet workshop, in proc. of VTC Spring 2011.

[26] S. Fortune et al., WiSE Design of Indoor Wireless Systems: Practical Computation and Optimization, IEEE Computational Science \& Engineering, vol. 2, no. 1, pp. 58-68, spring 1995.

[27] M. Ajmone Marsan, L. Chiaraviglio, D. Ciullo, M. Meo, Switch-Off Transients in Cellular Access Networks with Sleep Modes, GreenComm 4, Kyoto, Japan, June 2011. 


\section{Contents}

1 Introduction $\quad 4$

2 Related Work $\quad 5$

3 Optimal Sleep Modes in Homogeneous Networks 6

3.1 The network and traffic model . . . . . . . . . . . . . . . . . 6

3.2 The energy consumption model . . . . . . . . . . . . . . . . . . . 7

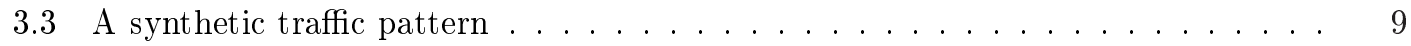

3.4 Measured Traffic patterns . . . . . . . . . . . . . . . . . . . . . . . . . . . . . . .

3.5 Sleep Modes with Deployment Constraints . . . . . . . . . . . . . . . 12

4 Heterogeneous Networks $\quad 15$

4.1 Case Study . . . . . . . . . . . . . . . . . . 18

5 Conclusions $r$ 


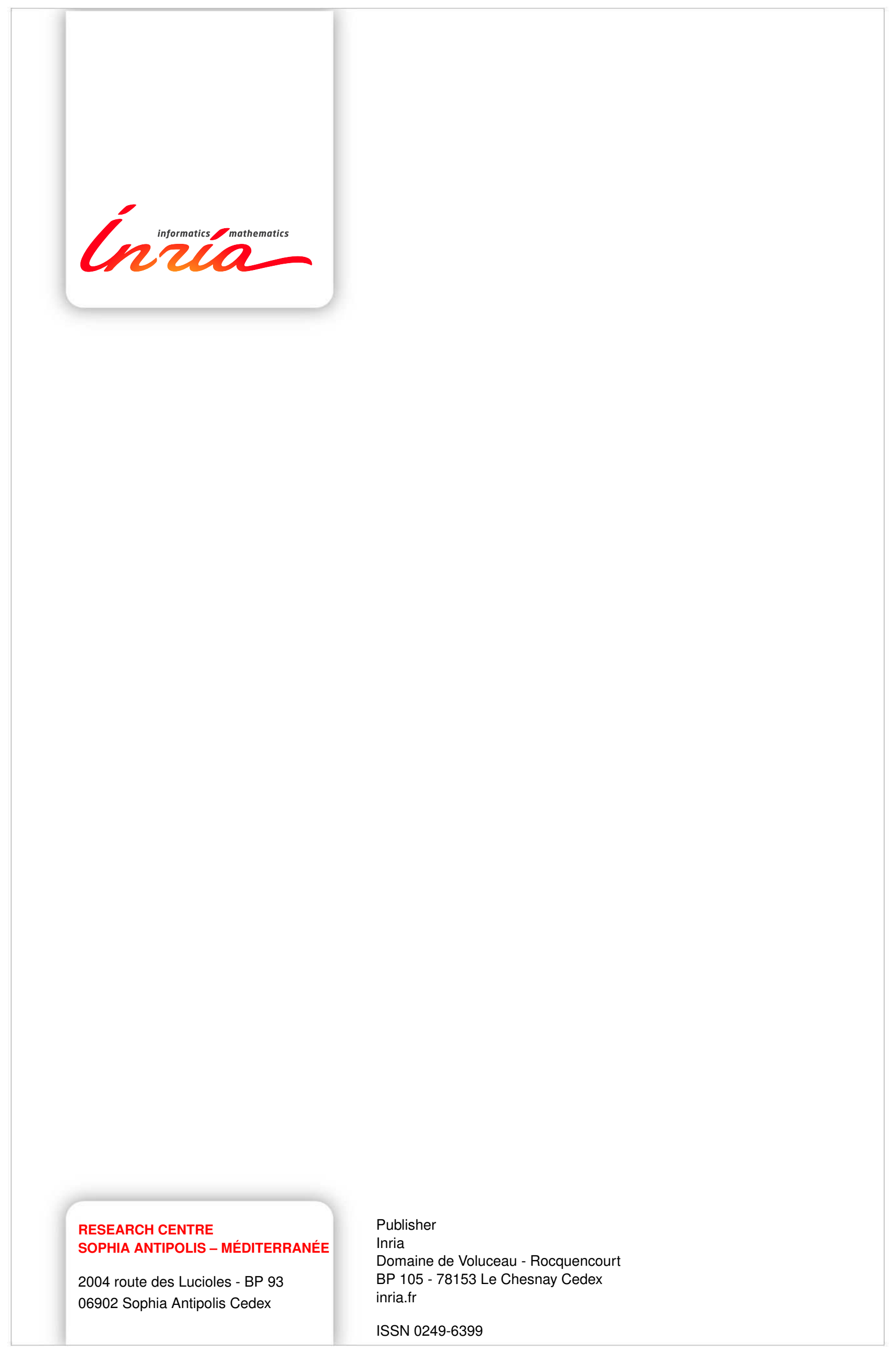

